\title{
Selected schedules of reinforcement in the black-tailed prairie dog (Cynomys ludovicianus)
}

\author{
GENE E. TODD and DENNIS C. COGAN \\ Texas Tech University, Lubbock, Texas 79409
}

\begin{abstract}
Wild black-tailed prairie dogs were run on FR, FI, VR, and VI schedules for Noyes pellet reinforcement. Cumulative barpress responses, postreinforcement pause lengths, and responses per second were recorded. The highest response rates occurred in the VR schedules, with the lowest response rates coming in the FI schedules. Fixed-ratio schedules had the longest postreinforcement pauses, VI schedules had the shortest. At the upper levels of the fixed-ratio schedules (FR 90-100), the animals ceased to respond consistently. Generally, data from prairie dogs were consistent with data reported in studies from other mammalian species.
\end{abstract}

The black-tailed prairie dog (Cynomys ludovicianus), a representative from the superfamily Sciuroidae (Walker, 1964), is a species well suited to biological and psychophysiological research. Although Cynomys is not a routinely used laboratory animal, researchers have successfully documented its natural and laboratory behaviors (Anthony, 1955; King, 1955; Koford, 1958), developmental phases (Johnson, 1927), reproductive physiology and courtship behaviors (Anthony \& Foreman, 1951; Anthony, 1952, 1953), and its visual sensitivity (Cain \& Carlson, 1968). In the psychophysiological literature, the prairie dog has been used to study habituation to drugs (Schreiber, Wood, \& Carlson, 1976) and intracranial stimulation (Cain, Skriver, \& Carlson, 1971; Carlson, Sanders, Tal, \& Wood, 1975). In addition, a stereotaxic atlas of its forebrain has been prepared (Carlson \& Knott, 1970).

Behavior of these xeric rodents under the applications of standard reinforcement schedules in the operant framework has not been extensively investigated. In the single study of instrumental learning that we found, Boice and Witter (1970) reported considerable difficulty in obtaining and maintaining basic operant schedules with Cynomys using water as a reinforcer. The selection of water as a reinforcer may, however, have been inappropriate as, normally, the wild prairie dog does not ingest free-standing water (King, 1955). In addition, they found poor alternation responding

\footnotetext{
This research was funded by a Texas Tech University Summer Research Assistantship granted to G.E.T. The authors gratefully acknowledge the assistance of Miss Lee Barnard for typing the manuscript, and Ms. Carole A. Bohn for preparation of the graphs. Portions of this paper were presented to the 17 th Annual Meeting of the Psychonomic Society, St. Louis, November 11, 1976. Requests for reprints should be addressed to Dennis C. Cogan.
}

and considerable torpor in deprived prairie dogs.

Since some of our colleagues had maintained a number of prairie dogs in our laboratory for several years, and we observed their adaptability in a variety of physiological test situations (Cain et al., 1971; Carlson et al., 1975), we were somewhat surprised at the poor learning performance of the prairie dogs in the Boice and Witter (1970) study. Good or typical operant performance depends upon the occurrence of an appropriate reinforcer contingent upon the response. As already mentioned, the decision to use water by Boice and Witter (1970) may have been unfortunate. Also, it has been our observation that severe deprivation, particularly on a restricted access schedule such as the one used by Boice and Witter, is a difficult adjustment for wild rodents.

Since we were certain that Cynomys could perform well in an operant task, and because one of the more salient characteristics of the comparative research published in the current psychological literature is the relatively few species used (Beach, 1950; Bitterman, 1965, 1975; Lockard, 1968), it seemed worthwhile to assess the barpress performance of the black-tailed prairie dog. Four basic schedules of reinforcement were used: fixed ratio (FR), fixed interval (FI), variable ratio (VR), and variable interval (VI). The major purposes of the present study were (1) to determine if there were parameters of reinforcement and deprivation which would produce good consistent operant responding, and (2) to determine if there were any major differences between the operant performance of the prairie dog and other mammalian species.

\section{METHOD}

\section{Subjects}

Eight black-tailed prairie dogs were live-trapped from the 
resident colony at a nearby state park and were housed in pairs in small wiremesh primate cages in the Psychology Department's animal colony. Ambient room temperature was kept at approximately $22^{\circ} \mathrm{C}$, with lighting sequenced $12 \mathrm{~h}$ on, $12 \mathrm{~h}$ off, per $24-\mathrm{h}$ cycle. Four of the animals were male, four female and all were judged to be from 2-3 years of age on the basis of degree of wear of the molar teeth. Regular diet consisted of Purina Laboratory Chow supplemented with commercially prepared rolled oats. Water was available at all times in standard water-bottle/sipper-tube configuration.

\section{Apparatus}

Two BRS-LVE single-bar operant chambers housed in soundattenuating cubicles ware used. A Digital Equipment Corporation LAB-K and standard relay circuitry were used to control the schedules, and were housed in an adjacent room. Responses were counted on digital counters, and cumulative records were taken on Harvard Model C-3 cumulative recorders. Galvanized hardware cloth was placed on the floor of the chambers to prevent the animals' paws from going between the floor bars. Masking noise was provided with a Grason-Stadler noise generator, EB1207, with intensity within the chamber of $65 \mathrm{~dB}$ SPL. Standard BRS-LVE pellet dispensers delivered the reinforcement.

\section{Procedure}

The animals had gained quite a bit of weight during the acclimatization period (mean lab weight of $1,400 \mathrm{~g}$ vs. wild weight of around $1,000 \mathrm{~g}$ ), due presumably to inactivity and ready availability of food. Body weight was reduced to approximately $70 \%-75 \%$ of the laboratory weight, about the same as the wild weight. One animal died after a prolonged illness.

Reinforcement consisted of one 45-mg Noyes "A" formula pellet which was found, after initial unsuccessful attempts to use water and sucrose pellets, to result in the most consistent performance. Animals were run for a single 30 - or 45 -min session daily, with the 45-min sessions used when schedules were higher than FI 60 , VR 50, and VI 60 . The majority of the Phase 2 sessions were $30 \mathrm{~min}$ in length. All animals were initially handshaped by successive approximation to an FR 5 and, on the following day, shifted to one of the designated schedules. The animals were run for a minimum of 15 days on each schedule, or until performance stabilized. After each major schedule change (e.g., FR to VI), each animal was run for a minimum of 20 sessions. Sequences of schedules for each subject are shown in Table 1.

Lab Chow and rolled oats were given after each session to maintain weights within the specified range. The end of a session was signaled by the retraction of the manipulandum. Each reinforcement was marked by a brief presentation of a white cue light.

\section{RESULTS}

\section{Fixed-Ratio Schedules}

Response rates and postreinforcement pauses were considered separately for the FR schedules. Response rate was determined by dividing the total number of responses by the total time less the total postreinforcement pause time. For each subject, postreinforcement pause (PRP) durations increased, and response rate decreased, as a function of increases in the FR response requirement. These data are shown in Figure 1.

The direct relationship between ratio size and pause duration observed here agrees with the findings of previous reports for other species (e.g., Powell,
Table 1

Treatment Sequences

\begin{tabular}{|c|c|c|c|c|c|c|}
\hline \multirow[b]{2}{*}{ Subject } & \multicolumn{3}{|c|}{ Phase 1} & \multicolumn{3}{|c|}{ Phase 2} \\
\hline & Schedule & $\begin{array}{l}\text { Session } \\
\text { Time }\end{array}$ & $\mathrm{N}$ & Schedule & $\begin{array}{c}\text { Session } \\
\text { Time }\end{array}$ & $\mathrm{N}$ \\
\hline $15 \mathrm{R}$ & $\begin{array}{ll}\text { FR } & 20 \\
\text { FR } & 30 \\
\text { FR } & 40 \\
\text { FR } & 50 \\
\text { FR } & 60 \\
\text { FR } & 70 \\
\text { FR } & 80 \\
\text { FR } & 90\end{array}$ & $\begin{array}{l}30 \\
30 \\
30 \\
30 \\
30 \\
30 \\
30 \\
30\end{array}$ & $\begin{array}{l}15 \\
15 \\
16 \\
15 \\
16 \\
16 \\
16 \\
17\end{array}$ & & & \\
\hline 150 & $\begin{array}{lr}\text { VI } & 30 \\
\text { VI } & 45 \\
\text { VI } & 60 \\
\text { VI } & 90 \\
\text { VI } & 120 \\
\text { VI } & 150 \\
\text { VI } & 180 \\
\text { VI } & 120\end{array}$ & $\begin{array}{l}30 \\
30 \\
30 \\
45 \\
45 \\
45 \\
45 \\
45\end{array}$ & $\begin{array}{l}15 \\
16 \\
16 \\
15 \\
17 \\
16 \\
17 \\
17\end{array}$ & $\begin{array}{lr}\text { FR } & 20 \\
\text { FR } & 40 \\
\text { FR } & 80 \\
\text { FR } & 100\end{array}$ & $\begin{array}{l}30 \\
30 \\
30 \\
30\end{array}$ & $\begin{array}{l}20 \\
20 \\
21 \\
22\end{array}$ \\
\hline $16 \mathrm{R}$ & $\begin{array}{ll}\text { FR } & 30 \\
\text { FR } & 40 \\
\text { FR } & 50 \\
\text { FR } & 60 \\
\text { FR } & 70 \\
\text { FR } & 80 \\
\text { FR } & 90\end{array}$ & $\begin{array}{l}30 \\
30 \\
30 \\
30 \\
30 \\
30 \\
30\end{array}$ & $\begin{array}{l}16 \\
15 \\
16 \\
17 \\
16 \\
16 \\
17\end{array}$ & $\begin{array}{lr}\text { VI } & 30 \\
\text { VI } & 45 \\
\text { VI } & 60 \\
\text { VI } & 90 \\
\text { VI } & 120\end{array}$ & $\begin{array}{l}30 \\
30 \\
30 \\
45 \\
30\end{array}$ & $\begin{array}{l}20 \\
20 \\
21 \\
21 \\
20\end{array}$ \\
\hline 160 & $\begin{array}{ll}\text { VR } & 20 \\
\text { VR } & 30 \\
\text { VR } & 40 \\
\text { VR } & 50 \\
\text { VR } & 60 \\
\text { VR } & 70 \\
\text { VR } & 80 \\
\text { VR } & 90\end{array}$ & $\begin{array}{l}30 \\
30 \\
30 \\
30 \\
45 \\
45 \\
45 \\
45\end{array}$ & $\begin{array}{l}15 \\
16 \\
16 \\
15 \\
17 \\
17 \\
17 \\
17\end{array}$ & $\begin{array}{lr}\text { FI } & 30 \\
\text { FI } & 45 \\
\text { FI } & 60 \\
\text { FI } & 90 \\
\text { FI } & 120\end{array}$ & $\begin{array}{l}30 \\
30 \\
30 \\
30 \\
30\end{array}$ & $\begin{array}{l}21 \\
21 \\
21 \\
21 \\
21\end{array}$ \\
\hline $18 \mathrm{R}$ & $\begin{array}{lr}\text { FI } & 30 \\
\text { FI } & 45 \\
\text { FI } & 60 \\
\text { FI } & 90 \\
\text { FI } & 120 \\
\text { FI } & 150\end{array}$ & $\begin{array}{l}30 \\
30 \\
30 \\
45 \\
45 \\
45\end{array}$ & $\begin{array}{l}16 \\
16 \\
16 \\
16 \\
17 \\
17\end{array}$ & $\begin{array}{lr}\text { VR } & 20 \\
\text { VR } & 40 \\
\text { VR } & 60 \\
\text { VR } & 80 \\
\text { VR } & 100\end{array}$ & $\begin{array}{l}30 \\
30 \\
30 \\
30 \\
30\end{array}$ & $\begin{array}{l}21 \\
22 \\
21 \\
21 \\
21\end{array}$ \\
\hline & $\begin{array}{lr}\text { FI } & 30 \\
\text { FI } & 45 \\
\text { FI } & 60 \\
\text { FI } & 90 \\
\text { FI } & 120 \\
\text { FI } & 150\end{array}$ & $\begin{array}{l}30 \\
30 \\
30 \\
45 \\
45 \\
45\end{array}$ & $\begin{array}{l}16 \\
16 \\
16 \\
16 \\
17 \\
16\end{array}$ & & & \\
\hline
\end{tabular}

Note $-N=$ number of sessions. Session time is given in minutes.

1972; Skinner, 1961) in which a direct relationship between ratio size and pause duration was also found. An examination of cumulative records for the prairie dogs on FR schedules shows consistent PRPs followed by relatively steady responding until the next reinforcement was obtained. Inconsistent responding became more frequent with substantial increases in the FR requirement. Representative cumulative records for FR schedules are shown in Figure 2.

These records are consistent with those found in rat and gerbil, at least for the lower FR schedules, 


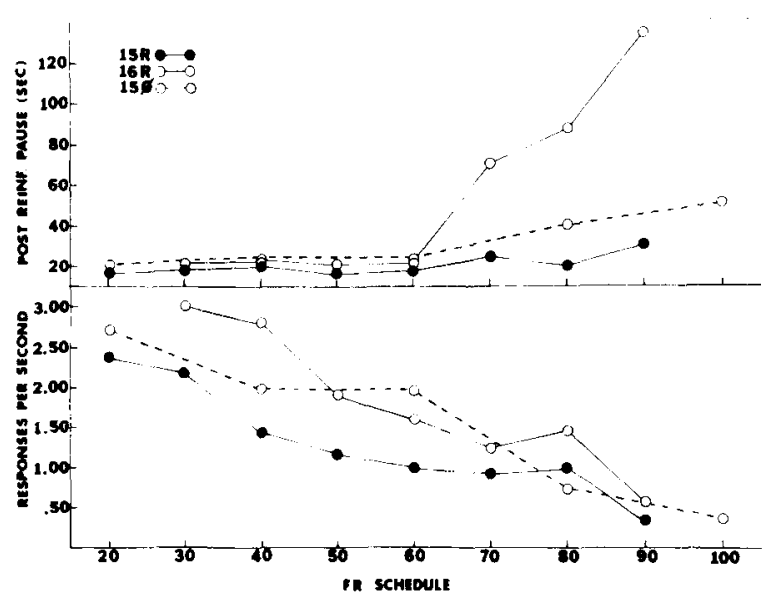

Figure 1. Post-reinforcement pause and response rates under fixed-ratio schedules. Each data point is the mean of the last four sessions per schedule.

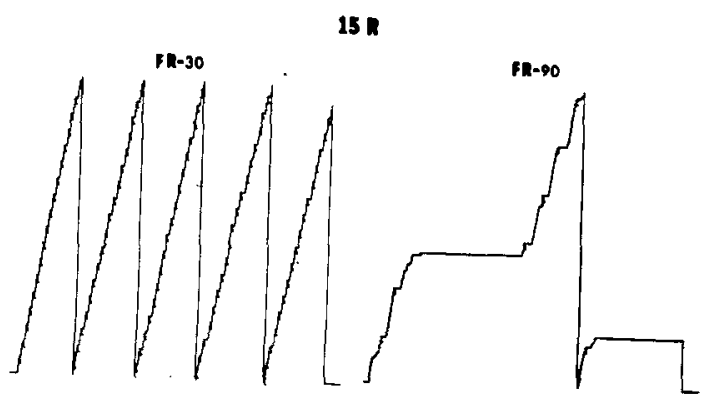

15.
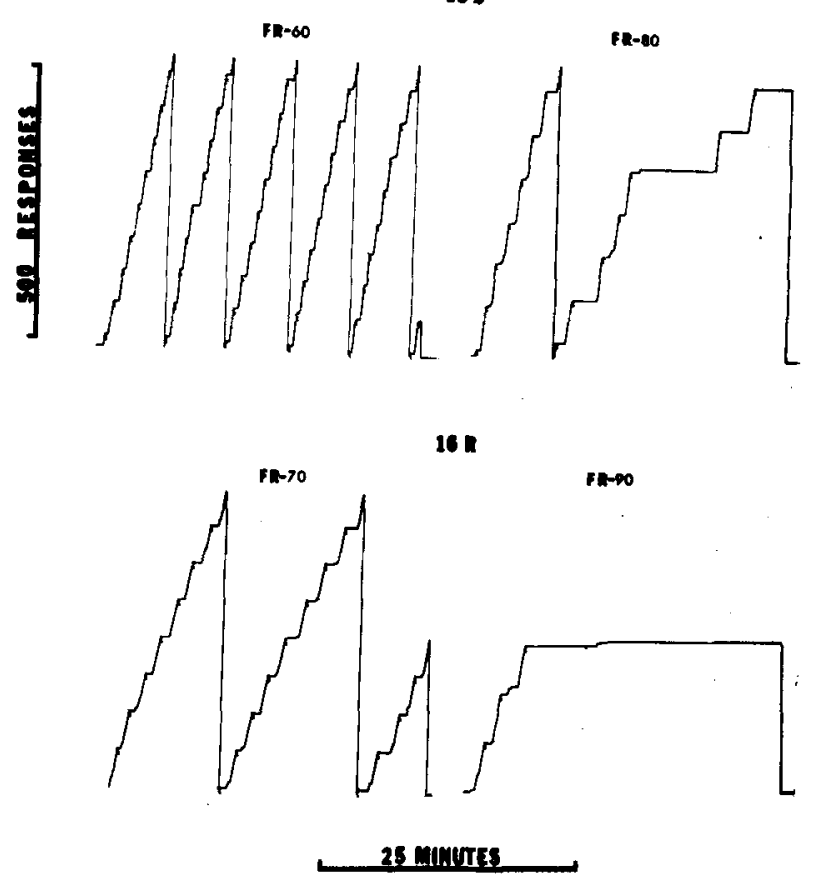

Figure 2. Representative fixed-ratio cumulative records for prairie dogs 15R, 159, and $16 R$.

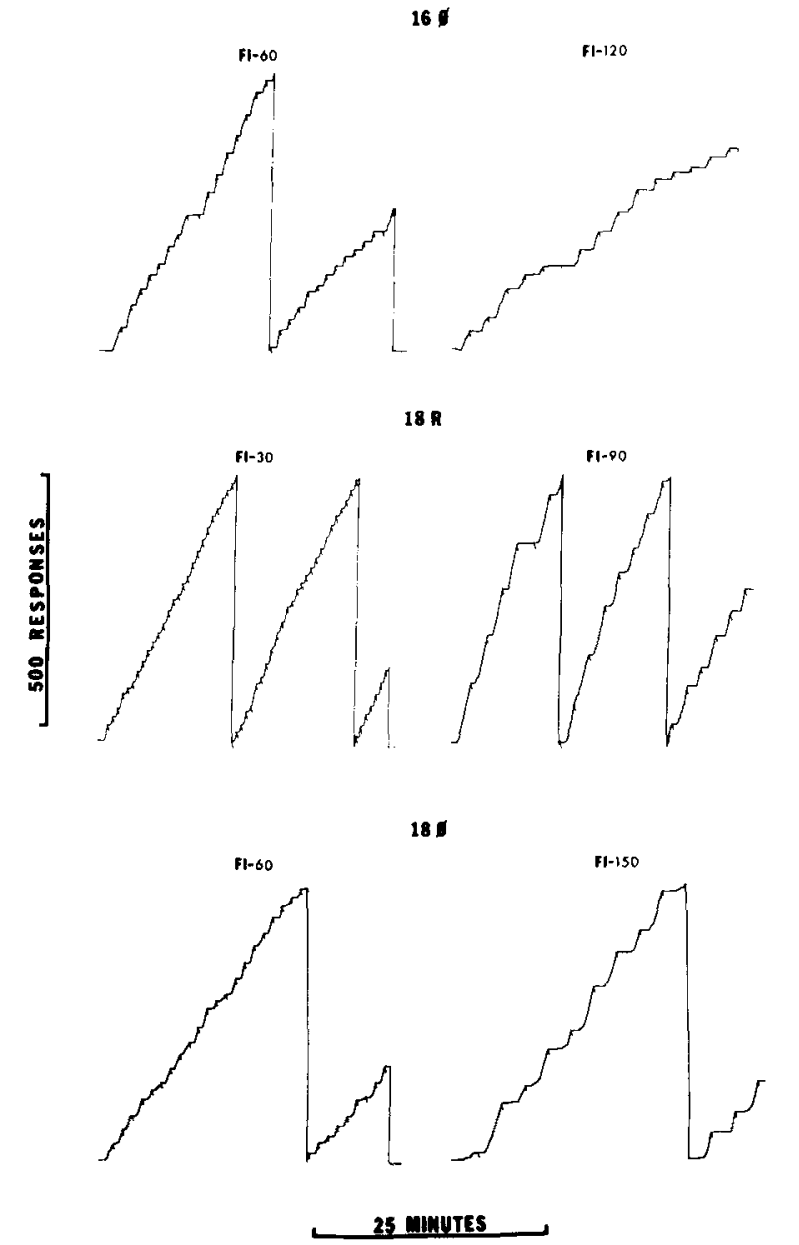

Figure 3. Representative fixed-interval cumulative records for prairie dogs 169, 18R, and 189.

but do no agree with consistent high rates of response displayed by rat and gerbil in the FR 80 to 100 schedules (VanderWeele, Abelson, \& Tellish, 1973).

\section{Fixed-Interval Schedules}

Fixed-interval schedules contained the longest PRPs of all the schedules used, a finding in agreement with Powell (1972), who used crows. The number of responses per second in this schedule were also the fewest for any of the schedules. This is in general agreement with the findings in the past (Ferster \& Skinner, 1957). As may be seen from Figure 3, the animals seldom responded during the interval. Towards the end of the interval, the animals responded at a high rate until reinforced and then abruptly ceased responding. Typically, an animal would get between $85 \%$ and $90 \%$ of the available reinforcements within a given session. This is a common finding with the rat and pigeon (Powell, 1972). Scalloping occurred across the schedules studied, a finding also common for pigeons 


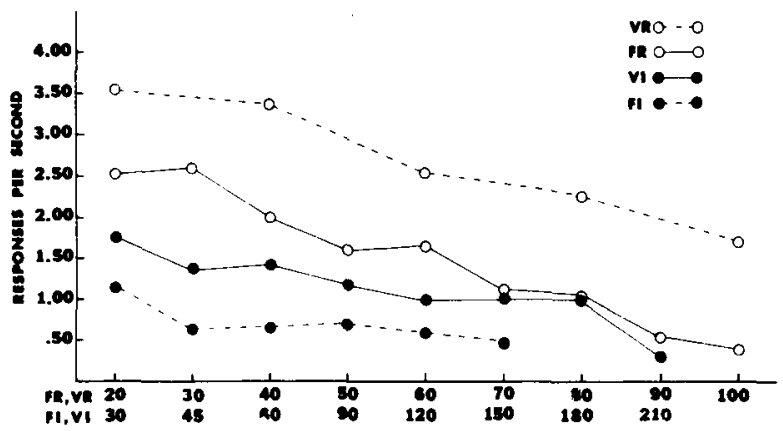

Figure 4. Response rates for FR, FI, VR, and VI schedules. Each data point is the mean of the last four sessions per schedule, across all animals run.

and rats (Ferster \& Skinner, 1957), but uncommon for gerbils (VanderWeele et al., 1973).

\section{Variable-Interval Schedules}

Variable-interval schedules were typified by the shortest PRPs of the schedules used. Average number of responses per second, however, was in general greater than in the FI schedules, yet lower than found in VR and FR schedules. These data are shown in Figure 4.

Variable-interval responding was usually regular, and robust at the longer intervals. Samples of the cumulative records resulting from this schedule are shown in Figure 5.

\section{Variable-Ratio Schedules}

Examination of the data revealed that the highest response rates occurred as a result of variable-ratio scheduling, a finding also reported by Herrnstein (1964) for pigeons, Powell (1972) for crows, and VanderWeele and Abelson (1973) for gerbils. Variable-ratio schedule cumulative response curves were characterized by high, consistent rates of responding, as may be seen in the samples of cumulative records shown in Figure 6.

\section{DISCUSSION}

The initial aim of this study was to determine what parameters of reinforcement would yield reliable schedule-controlled operant responding in wild prairie dogs. Results indicated that responding could be effectively maintained with food reinforcement over the four basic schedules used (FR, FI, VR, and VI), with disruption of behavior occurring only in high-ratio FR schedules. This disruption of responding is a clear difference between the operant performance of the prairie dog, and that reported for gerbils and rats. VanderWeele et al., (1973)

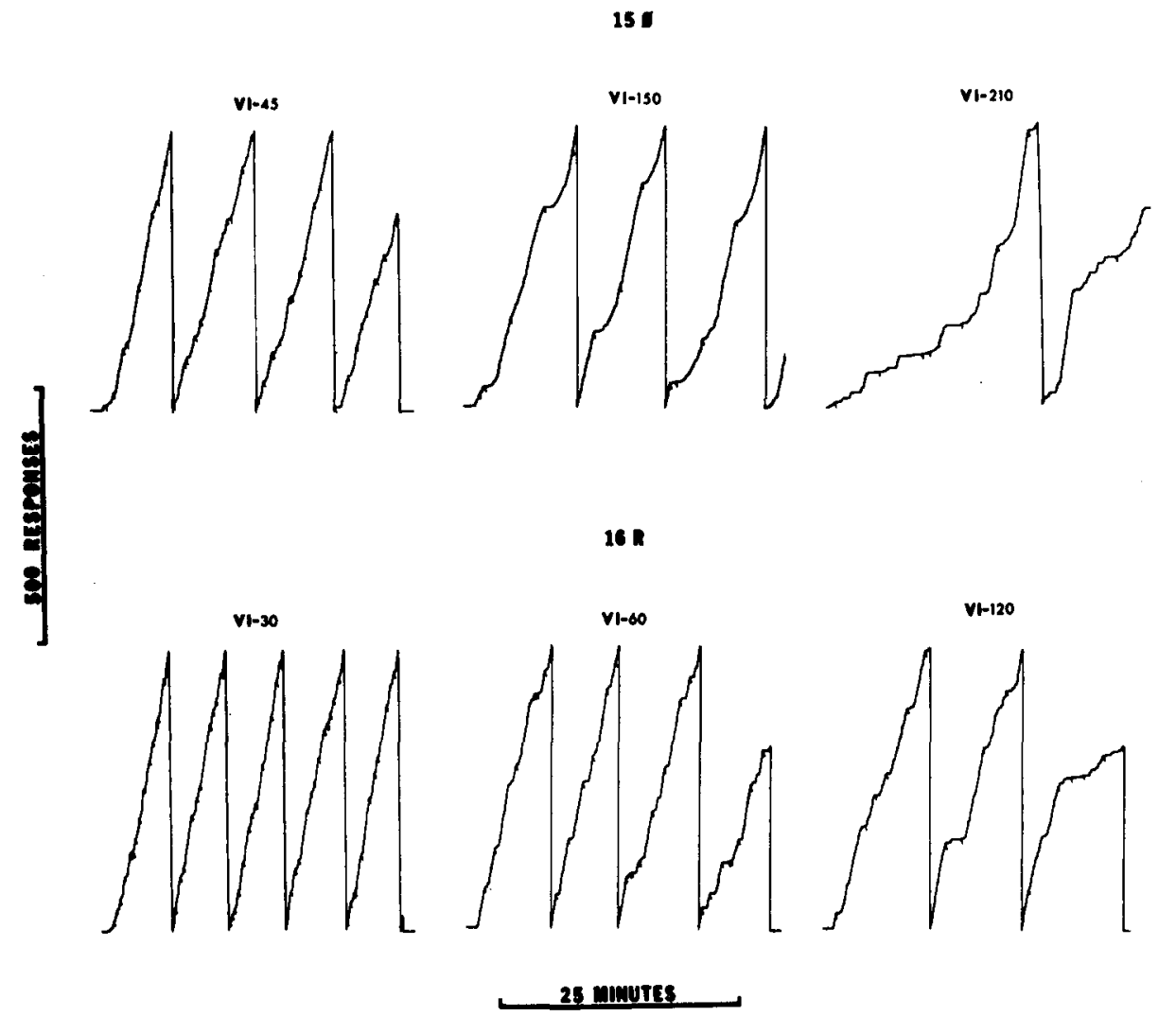

Figure 5. Representative variable-interval cumulative records for prairie dogs $15 \theta$ and $16 R$. 


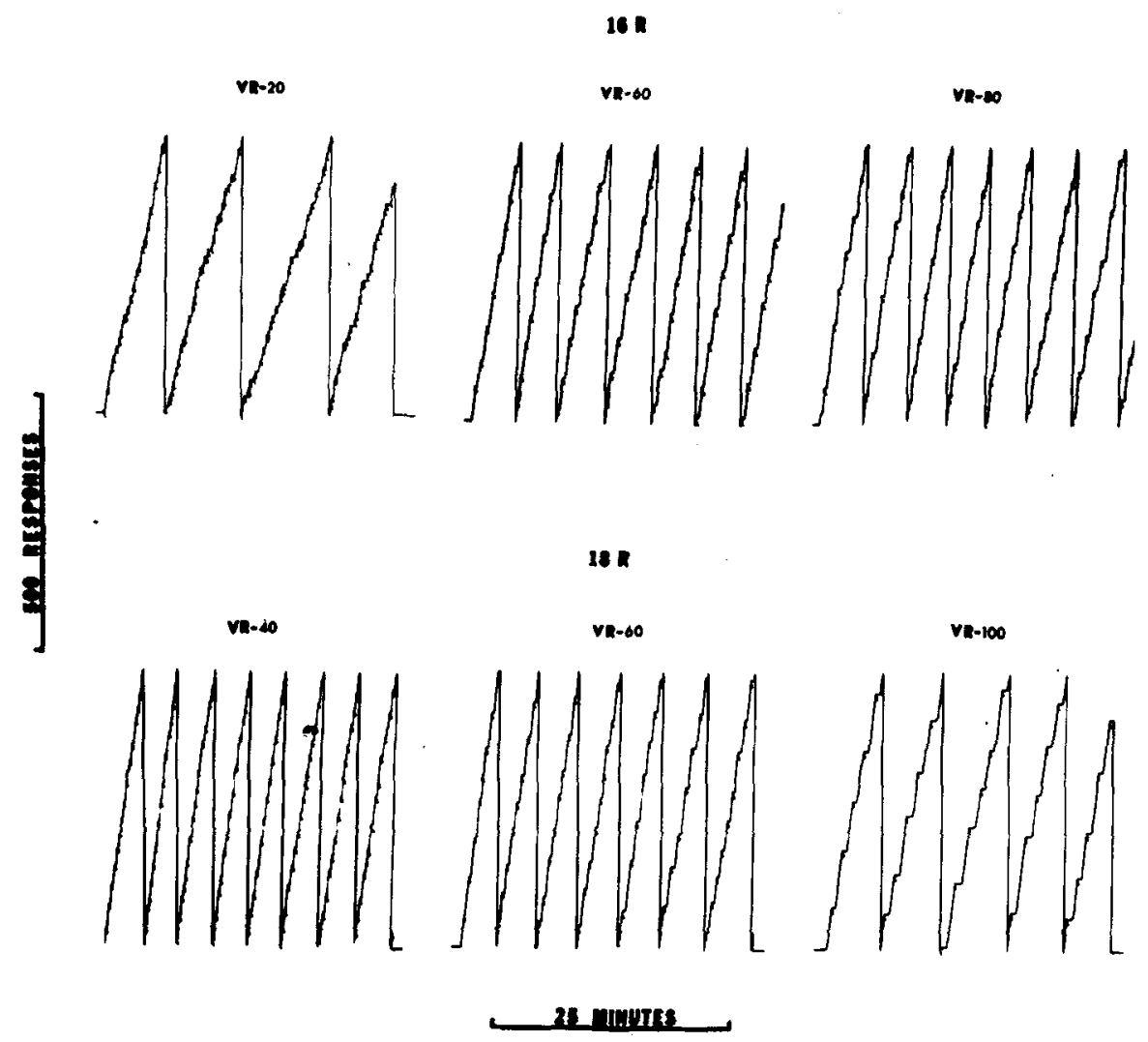

Figure 6. Representative variable-ratio cumulative records for prairie dogs 160 and $18 R$.

reported much more consistent response rates in the rat and the gerbil using FR schedules in the 80-100 range. While the reason for the difference in operant performance is not immediately clear, several possibilities exist.

The choice of type of reinforcing substance, or amount, may be more critical for Cynomys than for other species. The amount of effort expended in obtaining reinforcement in the high-ratio FR schedules may have interacted unfavorably with the nature of the reinforcement chosen and the relatively mild deprivation regimen. Clearly, although the reinforcer used was potent enough to establish operant performance, it could not maintain it at the effort required for the FR 80 and FR 90 schedules. It may be that a preferred "natural" reinforcer which contains some moisture, such as food eaten in the natural state, might have proven more effective than the dry pellets given. Also, some seasonal influences may have been present. The bulk of the data for the high FR schedules were collected during the winter months. Although they do not hibernate, wild $C$. ludovicianus do tend to be less active in the winter (Koford, 1958). Consequently, performance may have been impaired during the winter months; data collection during spring or summer might have resulted in better high-ratio FR performance.

Despite some atypical response patterns, it is clear from our data that wild prairie dogs are quite capable of operant responding under the control of food reinforcement schedules. This is in contrast to the findings of Boice and Witter (1970), who reported considerable difficulty in establishing and maintaining consistent responding in prairie dogs with water used as reinforcement. We also experienced similar difficulties in our preliminary work in which we used distilled water, and $8 \%$ and $16 \%(w / w)$ sucrose solutions as reinforcers. This difficulty with liquid reinforcers was encountered despite the fact that the prairie dogs drank water in their home cages. As mentioned earlier, prairie dogs do not normally drink free-standing water in their natural environment (King, 1955). The effectiveness of food, relative to water-based compounds, in establishing and maintaining operant responding in the prairie dog would indicate that the reinforcement potential of a particular substance to a wild animal may be more closely related to it natural proclivities than to any experiences it has in captivity. This may well represent another type of constraint of a biological nature which must be taken into account by investigators interested in studying the generality of learning laws. 


\section{REFERENCES}

ANThony A. Physiology of reproduction in the male prairie dog. Unpublished doctoral dissertation, University of Chicago, 1952. (Cited by Anthony, 1955).

Anthony, A. Seasonal reproductive cycle in the normal and experimentally treated male prairie dog, Cynomys ludovicianus. Journal of Morphology, 1953, 93, 331-370.

ANTHONY, A. Behavior patterns in a laboratory colony of prairie dogs, Cynomys ludovicianus. Journal of Mammalogy, 1955, 36. 69-78.

Anthony, A., \& Foreman, D. Observations on the reproductive cycle of the black-tailed prairie dog (Cynomys ludovicianus). Physiological Zoology, 1951, 24, 242-248.

Beach, F. A. The snark was a boojum. American Psychologist, $1950,5,115 \cdot 124$.

Bitterman, M. E. Phyletic differences in learning. American Psychologist, 1965, 20, 396-410.

Bitterman, M. E. The comparative analysis of learning. Science, 1975. 188, 699-709.

Boice, R. \& W Witter, J. A. Motivating prairie dogs. Psychonomic Science, 1970, 20, 287-289.

CaIN, R. E., \& Carlson, R. H. Evidence for color vision in the prairie dog (Cynomys ludovicianus). Psychonomic Science, 1968, 13, 185-186.

Cain, R. E., Skruver, C. P., \& Carlson, R. H. Habituation of electrically induced readiness to gnaw. Science, 1971, 173, 262-264.

Carlson, R. H., \& Kott, J. N. The forebrain of the prairie dog (Cynomys ludovicianus) in stereotaxic coordinates. Acta Anatomica, 1970, 77, 321-340.

Carzson, R. H., Sanders, M. G., Tal., A., \& Wood, W. G. Attenuation of "acute" habituation by scopolamine in the blacktailed prairie dog (Cynomys ludovicianus). Joumal of Comparative and Physiological Psychology, 1975, 88, 335-341.
Ferster, C. B., \& Skinner, B. F. Schedules of reinforcement. New York: Appleton-Century-Crofts, 1957.

HerRnstein, R. J. Aperiodicity as a factor in choice. Joumal of the Experimental Analysis of Behavior, 1964, 7, 179-182.

Johnson, G. E. Observations on young prairie-dogs (Cynomys ludovicianus) born in the laboratory. Journal of Mammalogy, $1927,8,110-115$

KInG, J. A. Social behavior, social organization, and population dynamics in a black-tailed prairie dog town in the Black Hills of South Dakota. Contributions from the Laboratory of Vertebrate Biology, 1955, 67, 1-123.

Koford, C. B. Prairie dogs, whitefaces, and blue gramma. Wildlife Monographs, 1958, No. 3, 1-78.

LocKARD, R. B. The albino rat: A defensible choice or a bad habit? American Psychologist, 1968, 23, 734-742.

Powell, R. W. Responding under basic schedules of reinforcement in the crow. Journal of Comparative and Physiological Psychology, 1972, 79, 156-164.

Schreiber, H. L., Wood, W. G., \& Carlson, R. H. Tolerance in methylphenidate-induced locomotor activity in prairie dogs (Cynomys ludovicianus). Psychopharmacologia, Berlin. 1976, 46. 111-113.

SkInNer, B. Cumulative record. New York: Appleton-CenturyCrofts, 1961.

VANDERWeEle, D. A., \& Abelson, R. M. Selected schedules of reinforcement in the Mongolian gerbil. Psychological Reports, $1973,33,99-104$.

VanderWeele, D., Abelson, R., \& Tellish, J. A comparison of ratio behavior in the gerbil and white rat. Bulletin of the Psychonomic Society, 1973, 1, 62-64.

W ALKER, E. P. Mammals of the world (2 vols.). Baltimore: Johns Hopkins Press, 1964.

(Received for publication November 9, 1977; revision accepted February 28, 1978.) 